\title{
Influence of Reciprocating NiTi Instruments on the Accuracy of Apex Locator Integrated Endomotors During Simultaneous Working Length Determination
}

\author{
Öznur Sarıyılmaz ${ }^{1}$, Evren Sarıyılmaz², Cangül Keskin ${ }^{3}$ \\ ${ }^{1}$ Ordu Oral and Dental Health center, Ordu, Turkey \\ ${ }^{2}$ Department of Endodontics, Faculty of Dentistry, Ordu University, Ordu, Turkey \\ ${ }^{3}$ Department of Endodontics, Faculty of Dentistry, Ondokuz mayıs University, Samsun, Turkey \\ Received: 10 March 2020, Accepted: 04 April 2020, Published online: 30 April 2020 \\ (C) Ordu University Institute of Health Sciences, Turkey, 2020
}

\begin{abstract}
Objective: To compare simultaneous working length determination efficiency and electrical resistance of thermally treated NiTi files and their counterfeits.

Methods: Access cavities were prepared for sixty human mandibular premolar teeth, which were then numbered with a marker. Actual working length was determined visually by introducing a \#10 K-file into the root canal and the reference point was marked for further steps. By using flowable composite, the teeth were fixed at the cementoenamel junction to a hole in the center of a glass bottle cap and a second hole prepared on it for lip clip. Alginate impression material was filled into glass bottle then the tooth was embedded into it. Experimental models randomly divided into 6 groups as Group WOG (WaveOne Gold), Group WO (WaveOne), Group W+ (Superline W+), Group RB (Reciproc Blue), Group R (Reciproc), Group V (Superline V). Root canals were prepared until the endomotor stopped when reaching the apical foramen and the silicon stopper was moved to the previously marked reference point to determine the simultaneous working length. The electrical resistance of the files (from tip of file to notch of the shaft) was measured using a multimeter.

Results: No readings could be obtained via apex locator for Group V. Group W+ was significantly less accurate compared the other groups $(p<0.05)$. No significant difference was found among the groups WO, WOG, R, and RB ( $p>0.05)$.

Conclusion: Thermal treatments of NiTi alloys had no effect on the accuracy of simultaneous working length determination. However, counterfeit endodontic files failed to show of accurate simultaneous working length determination.
\end{abstract}

Key words: Electrical resistance, Endodontics, Nitinol, Root Canal Preparation

Suggested Citation: Sariyilmaz O, Sariyilmaz E, Keskin C. Influence of reciprocating NiTi instruments on the accuracy of apex locator integrated endomotors during simultaneous working length determination. Middle Black Sea Journal of Health Science, 2020; $6(1): 70-75$

Address for correspondence/reprints:

Öznur Sarıyılmaz

Telephone number: +90 (505) 2416390

ORCID-ID 0000-0003-4263-6851

E-mail: oznursariyilmaz@yahoo.com
DOI: $10.19127 / \mathrm{mbsjohs.701606}$

Note: The data obtained from the preliminary study of this study was presented in the 25th of Turkish Dental Association International Dental Congress as an oral presentation. 


\section{Introduction}

Accurate determination of the working length is among the indispensable steps of endodontic treatment. Failure to measure the working length correctly could result in two possibilities: the insufficient chemo-mechanical root canal preparation, which might lead to failure of endodontic treatment eventually due to untouched sites in the root canal system harboring microorganisms and pulp remnants (Sipavičiūtè and Manelienè, 2014); and over-instrumentation of the root canal, leading to acute periapical irritation as a result of extruded instrumentation, irrigants, pulp remnants, microorganisms, and their toxins. Moreover, the overfilling of a root canal might follow overinstrumentation if the over-instrumentation is not corrected, which can result in treatment failure (Ricucci et al., 2011). Radiographs and electronic apex locators are primarily used to determine the working length in clinics (Orafi and Rushton, 2013; Martins et al., 2014).

Electronic apex locators' fundamental operating principles are mainly based on the assumption that living human tissues have certain electrical characteristics (Nekoofar et al., 2006). These devices measure the resistance or the impedance changes of the dental tissues to determine the apical foramen (Nekoofar et al., 2006).

Manufacturers have integrated electronic apex locators into endodontic motors to allow simultaneous working length control during root canal preparation (Wiggler et al., 2014). Most of these apex locator integrated endomotors that have two selections regarding how they signal to reach the apical foramen. They could automatically stop instrumentation or turn the file reverse to easily withdraw it from the root canal; the latter property had been associated with lower postoperative pain levels (Arslan et al., 2017).

$\mathrm{NiTi}$ file systems have become common armamentarium among the general dentists and specialists for endodontic treatment for over the past two decades. Reciproc Blue [(RB) (VDW, Munich, Germany)] and WaveOne Gold [(WOG) (Dentsply Sirona, Ballaigues, Switzerland)] are among the most popular NiTi file systems; both are reciprocal, singlefile instruments intended for single use. Similarly, they are developed from their ancestor file systems (Reciproc and WaveOne, respectively) by enhancing file designs and applying thermal treatment. As a result of the thermal treatment, a modified titanium oxide layer is produced upon the surface of the instruments. The thickness of the titanium oxide layer gives the instruments either its blue or gold color and compensates the cutting ability while the innovative thermal treatment increases cyclic fatigue resistance and flexibility of the instruments. NiTi instruments have recently been upgraded by application of thermal treatments before or after manufacturing to minimize the instrument separation rate, while widespread consensus has been reached upon singleuse of instruments in consideration with mechanical and biological concerns (Gavini et al., 2018). However, single-use of such expensive instruments with high-quality standards is a financial burden for common clinicians. Therefore, especially in developing countries, gray markets that claim to market cheaper equivalent dental products would appear without a proper introduction of the alloy or kinematics of the instruments. Unfortunately, these instruments are counterfeit and usually far from meeting expectations (Rodrigues et al., 2018).

Here we address two principal questions:

1 . Is there any difference between the counterfeit and the original thermally-treated NiTi file systems on working length determination efficiency of apex locator integrated endomotor during root canal preparation?

2. Is there any difference in electrical resistivity between the NiTi file types, and does this contribute to working length determination?

Null hypotheses of this study were;

1. Counterfeit files detrimentally affects simultaneous working length determination via electronic apex locator integrated endomotors.

2. Electrical resistivity of the NiTi files is related with working length determination via electronic apex locator integrated endomotors.

\section{Methods}

The local university clinical research ethics committee approved the protocol of this study (KAEK 2018-26). A priori sample size determination was performed using the effect size calculated from a previous study (Guise et al., 2010). Ten specimens were indicated as the minimum ideal size after sample size determination with $\mathrm{X} 2$ family and goodness of fit contingency tables (0.05 alpha-type error and 0.80 power beta) (G*Power 3.1 for Macintosh; Heinrich Heine, Universitat Dusseldorf, Dusseldorf, Germany).

Sixty extracted human mandibular premolar teeth with a single root, single canal, and fully developed roots were collected for this study. Endodontic access cavities were prepared using diamond fissure bur under water-cooling. Every specimen was numbered using a marker. Then, a \#10 K-file was inserted into the root canal until the tip of the file seen at the apical 
foramen, and then $0.5 \mathrm{~mm}$ was subtracted from the measurement to determine the working length of every specimen. A reference point on the crown was marked to be used during simultaneous working length determination. To blind the operator, the working lengths of the samples were recorded according to their assigned specimen number by one of the researchers (C.K.).

Sixty experimental models were prepared using the teeth. Each of the teeth was fixed using flowable composite (Bisco, Inc, Schaumburg, IL) at the cementoenamel junction to a hole in the center of a glass bottle cap. Crowns of teeth were left outside of the glass bottle. A second hole for the lip clip of the VDW Gold Reciproc Endomotor (Munich, Germany) was also made in the cap of the bottle. Afterward, the bottle was filled with alginate impression material, and then the sample, which was attached to the bottle cap, was embedded into it. All experimental models were randomly divided into six groups as below:

Group WOG: WaveOne Gold (Primary 25\#, 25 $\mathrm{mm}$, gold heat-treated NiTi alloy)

Group WO: WaveOne (Primary 25\#, $25 \mathrm{~mm}$, m-wire NiTi alloy)

Group W+: Superline W+ file (primary 25\#, 25 $\mathrm{mm}$, gold-wire NiTi alloy, counterfeit of WOG) (Shenzhen Superline Technology Co. Ltd, Shanghai, China) (http://en.supline.com/product/detail/99.html)

Group RB: Reciproc Blue (R25, 25 mm, Blue heat-treated NiTi alloy)

Group R: Reciproc (R25, 25 mm, m-wire NiTi alloy)

Group V: Superline V file (R25 $25 \mathrm{~mm}$, austenite alloy, counterfeit of RB) (Shenzhen Superline Technology Co. Ltd, Shanghai, China) (http://en.supline.com/product/detail/97.html)

The VDW Gold Reciproc endomotor was set to the "Reciproc All" mode for root canal preparations for all groups. The apex locator mode of the endomotor was set to stop when the file reaches the apical foramen during root canal preparation. The canals were irrigated with $5 \mathrm{~mL}$ of $5.25 \% \mathrm{NaOCl}$ during preparation using a $30-\mathrm{G}$ side-vented needle attached to the plastic syringe placed $2 \mathrm{~mm}$ short of the working length. An experienced endodontist (E.S) prepared all teeth in gentle in-out pecking motions. The flutes of the file were cleaned after every three pecking movements. The preparation was continued until the endomotor stops due to reaching the apical foramen. Then, the silicone stopper was positioned to touch the reference point, which was marked previously. Next, the length of the file was measured using the same digital micrometer (DHDL 25 $\mathrm{mm} / 0.001 \mathrm{~mm}$ digital Micrometer, China) that was used for the actual working length determination step. Then, the first and second measurements were compared, and the reading of apex locator was classified as $-1.0 \mathrm{~mm},-0.5 \mathrm{~mm}$, correct, $+0.5 \mathrm{~mm}$, $+1.0 \mathrm{~mm}$ and $>1.0 \mathrm{~mm}$ according to the actual length of the canal.

The electrical resistance of the files, which might have an effect on working length determination via electronic apex locators, was also measured using a multimeter device (TT T-ECHNI-C Vc97 Digital Multimeter, China) according to manufacturer's recommendations. Measuring probes of the multimeter were connected to the tip of each file and to the notch of the shaft.

\section{Statistical analysis}

Differences among the ability of instruments to measure working length were analysed using chisquare test with 5\% significance threshold (SPSS v. 23. 0, IBM, Chicago, IL, USA).

\section{Results}

Table 1 presents the frequency of the determination rates of the tested instruments. The group $\mathrm{V}$ was not included in the statistical analyses because no readings could be obtained via the apex locator integrated endomotor. No significant difference was found among the WO, WOG, R, and $\mathrm{RB}$ file systems about working length determination $(\mathrm{p}=0.628)$; however, the group $\mathrm{W}+$ was statistically less accurate $(\mathrm{p}=0.002)$ (Table 1). Table 2 presents the electrical resistance of the tested NiTi files. The Superline $\mathrm{W}+$ and Superline V files have significantly more electrical resistance values compared to the WO, WOG, R, and RB file systems (Table 2). 
Table 1. Accurate simultaneous working length determination rates via the NiTi files that mounted on electronic apex locator integrated endomotor

\begin{tabular}{lllllllllllll}
\hline & \multicolumn{2}{c}{ WOG } & \multicolumn{2}{c}{ WO } & \multicolumn{2}{c}{ W+ } & \multicolumn{2}{c}{ R } & \multicolumn{2}{c}{ RB } & \multicolumn{2}{c}{$\mathbf{V}$} \\
\hline EAL measurement & $\mathbf{n}$ & $\%$ & $\mathbf{n}$ & $\%$ & $\mathbf{n}$ & $\%$ & $\mathbf{n}$ & $\%$ & $\mathbf{n}$ & $\%$ & $\mathbf{n}$ & $\%$ \\
\hline$-1 \mathrm{~mm}$ & - & - & 1 & 10 & - & - & 1 & 10 & - & - & - & - \\
$-0.5 \mathrm{~mm}$ & 3 & 30 & - & - & - & - & 2 & 20 & 2 & 20 & - & - \\
Correct & 7 & 70 & 7 & 70 & 1 & 10 & 6 & 60 & 6 & 60 & - & - \\
$+0.5 \mathrm{~mm}$ & - & - & 1 & 10 & 4 & 40 & - & - & - & - & - & - \\
$+1 \mathrm{~mm}$ & - & - & 1 & 10 & 1 & 10 & 1 & 10 & 2 & 20 & - & - \\
$>$ & $-1 \mathrm{~mm}$ & - & - & - & 4 & 40 & - & - & - & - & - & - \\
\hline
\end{tabular}

Table 2. Electrical resistance of the files $(\Omega)$ and kind of NiTi alloy

\begin{tabular}{ccccccc}
\hline & WOG & WO & W+ & $\mathbf{R}$ & $\mathbf{R B}$ & $\mathbf{V}$ \\
\hline NiTi Alloy type & $\begin{array}{c}\text { Gold heat } \\
\text { treatment }\end{array}$ & M-wire & Gold-wire & M-wire & $\begin{array}{c}\text { Blue Heat } \\
\text { Treatment }\end{array}$ & Austenite \\
\hline $\begin{array}{c}\text { Electrical } \\
\text { resistance }(\Omega)\end{array}$ & 0.1 & 0.1 & 0.6 & 0.1 & 0.1 & 1.0 \\
\hline
\end{tabular}

\section{Discussion}

Endodontic NiTi instruments are usually manufactured using equiatomic NiTi alloy due to its unique properties, such as the shape memory effect and superelasticity (Thompson, 2000; Shen et al., 2013). These superior properties mainly depend on the unique transformation ability of the crystallographic structure of the alloy induced by temperature or physical stress (Zupanc et al., 2018). Despite these favorable abilities of the material, separation risk of the NiTi instrument in the root canal is still a matter of concern (Shen et al., 2013). If a NiTi instrument is broken in the root canal, the case would become more complicated and it may even result in tooth extraction (Madarati et al., 2013). Therefore, many manufacturers focus their efforts to improve the mechanical properties of endodontic $\mathrm{NiTi}$ instruments by surface, mechanical, and thermal treatments to increase flexibility and enhance resistance to fracture (Zupanc et al., 2018).

One of the primary purposes of this study is to seek an answer to the question of does the crystallographic structure of the NiTi alloy influence the effectiveness of the apex locator that integrated into an endomotor. Therefore, Reciproc and WaveOne files, which are produced by using $\mathrm{m}$-wire alloy, were compared to their successors, which are $\mathrm{RB}$ and WOG that are thermally treated. The results of this study revealed that there was no statistically significant difference among these endodontic instruments regarding their effect on working length determination. However, the tested counterfeit files failed to accurately determine the working length. As discussed above, the electronic apex locators were developed upon the electrical principles. Therefore, electrical resistances of the files, which might have effect working length determination via electronic apex locators, were also measured for this study, revealing that the counterfeit files have much greater electrical resistance values compared to the original files (Table 2).

The electrical resistance of a material depends on three main factors: resistivity, length, and crosssectional area of the material (Nekoofar et al., 2006). The length factor was constant for all groups in this study due to the study design. However, the crosssectional area of the files was slightly different due to taper differences in the tested files. Besides, the electrical resistivity of NiTi alloy phases is differing among the austenite $(100 \times 10-6 \mathrm{ohm}-\mathrm{cm}$ for $55-$ Nitinol austenite) and martensitic ( $80 \times 10-6 \mathrm{ohm}-\mathrm{cm}$ for 55-Nitinol martensite) (Thompson, 2000). Therefore, it is logical to expect to have electrical resistance differences among the tested files due to the reasons discussed above. However, the electrical resistance values of the WO, WOG, R, and RB files were the same $(0.1 \Omega)$. The most reasonable explanation for this is that the sensitivity of the multimeter must be insufficient to determine such tiny differences. However, the $\mathrm{V}$ files and $\mathrm{W}+$ files have much more electrical resistance that could easily be determined by using the multimeter. However, the 
$\mathrm{V}$ and $\mathrm{W}+$ files showed greater electrical resistance that could easily be determined by using the multimeter. Higher electrical resistance and failure to provide accurate working length determination via electronic apex locator integrated endomotors using $\mathrm{V}$ and $\mathrm{W}+$ files might be related with their alloy type of either handle or working part of the instruments or manufacturing process.

Previous studies had reported that counterfeit or counterfeit dental products are rapidly introduced into dental markets and are usually of insufficient quality for use in dental interventions (Rodrigues et al., 2018; Hancocks, 2016; Proffitt, 2016). In line with these articles, the results of this study revealed that the counterfeit endodontic files might cause the failure of accurate simultaneous working length determination via apex locator integrated endomotors.

\section{Conclusion}

Within the limits of this study, thermal treatments on NiTi alloys have no effect on simultaneous working length determination via apex locator integrated endomotors. However, counterfeit endodontic files might cause the failure of accurate simultaneous working length determination

Ethics committee approval: The Ordu University Clinical Research Ethics Committee approved the protocol of this study (KAEK 2018-26).

Peer-review: Externally peer-reviewed.

Author Contributions: Conception: Ö.S., E.S. Design: Ö.S., E.S. Supervision: E.S. Fundings: Ö.S., E.S. Materials: Ö.S., C.K. Data Collection and/or Processing: E.S, C.K. Analysis and/or Interpretation: C.K. Literature Review: Ö.S. Writing: Ö.S. 10. Critical Review : E.S., C.K.

Conflict of Interest: No potential conflict of interest relevant to this article was reported.

Financial Disclosure: The authors declared that this study has received no financial support.

\section{References}

Arslan H, Güven Y, Karataş E, Doğanay E. Effect of the Simultaneous Working Length Control during Root Canal Preparation on Postoperative Pain. J Endod 2017; 43(9): $1422-7$. doi:10.1016/j.joen.2017.04.028
Gavini G, Santos MD, Caldeira CL, et al. Nickeltitanium instruments in endodontics: a concise review of the state of the art. Braz Oral Res. 2018; 32(suppl 1): e67. doi:10.1590/1807-3107bor2018.vol32.0067

Guise GM, Goodell GG, Imamura GM. In vitro comparison of three electronic apex locators. J Endod doi:10.1016/j.joen.2009.09.016

Hancocks S. Beware and be aware. Br Dent J 2016; 220(2): 43. doi:10.1038/sj.bdj.2016.36

Madarati AA, Hunter MJ, Dummer PM. Management of intracanal separated instruments. J Endod. 2013;39(5):569-581. doi:10.1016/j.joen.2012.12.033

Martins JN, Marques D, Mata A, Caramês J. Clinical efficacy of electronic apex locators: systematic review. J Endod. 2014;40(6):759-777. doi:10.1016/j.joen.2014.03.011

Nekoofar MH, Ghandi MM, Hayes SJ, Dummer PMH. The fundamental operating principles of electronic root canal length measurement devices. Int Endod J 2006; 39: 595-609. doi:10.1111/j.1365-2591.2006.01131.x

Orafi I, Rushton VE. The use of radiography and the apex locator in endodontic treatment within the UK: a comparison between endodontic specialists and general dental practitioners. Int Endod J 2013; 46: 355-64. doi: $10.1111 / \mathrm{j} .1365-$ 2591.2012.02127.x

Proffitt E. Counterfeit and Non-Compliant Dental Devices: The Dangers and How to Mitigate Them. Dent Update 2016; 43(4): 307-12. doi:10.12968/denu.2016.43.4.307

Ricucci D, Russo J, Rutberg M, Burleson JA, Spångberg LS. A prospective cohort study of endodontic treatments of 1,369 root canals: results after 5 years. Oral Surg Oral Med Oral Pathol Oral Radiol Endod 2011; 112(6): 825-842. doi:10.1016/j.tripleo.2011.08.003

Rodrigues CS, Vieira VTL, Antunes HS, De-Deus G, Elias CN, Moreira EJL, Silva EJNL. Mechanical characteristics of counterfeit Reciproc instruments: a call for attention. Int Endod J 2018; 51: 556-63. doi:10.1111/iej.12792

Shen Y, Zhou HM, Zheng YF, Peng B, Haapasalo M. Current challenges and concepts of the thermomechanical treatment of nickel-titanium instruments. J Endod 2013; 39(2): 163-172. doi:10.1016/j.joen.2012.11.005

Sipavičiūtė E, Manelienė R. Pain and flare-up after endodontic treatment procedures. Stomatologija. 2014; 16(1): 25-30. 
Thompson SA. An overview of nickel-titanium alloys used in dentistry. Int Endod J 2000; 33: 297-310. doi:10.1046/j.1365-2591.2000.00339.x

Wigler R, Huber R, Lin S, Kaufman AY. Accuracy and reliability of working length determination by Gold Reciproc Motor in reciprocating movement. J Endod. 2014;40(5):694-697. doi:10.1016/j.joen.2013.09.002

Zupanc J, Vahdat-Pajouh N, Schäfer E. New thermomechanically treated NiTi alloys - a review. Int Endod J 2018; 51(10): 1088-103. doi:10.1111/iej.12924. 